\title{
JOINT BOARD OF WHAT?
}

\author{
By C. P. Seager \\ Senior Lecturer in Psychiatry, Whiteley Wood Clinic, Sheffield
}

\begin{abstract}
Occasionally consultants are asked by their nursing colleagues to support an application to attend a Joint Board course. More often than not the response is to throw up one's hands in horror and say 'Not another management course. Don't nurses do any nursing these days?' I believe that if doctors knew a little more about the Joint Board and its courses they would press more vigorously for secondment of nurses for this purpose; it must be noted that the numbers of psychiatric nurses who attend is abysmally low. There are relatively few courses available throughout the country, and Areas seem unwilling to accept responsibility for putting on such training programmes. Even those which are available do not always receive adequate support, largely, no doubt, because so many psychiatric hospitals are under-
\end{abstract} staffed and cannot spare nurses to attend.

The Joint Board of Clinical Nursing Studies was set up in 1970 under the chairmanship of Sir Hedley Atkins to plan and monitor training courses for nurses already on the various Registers and Rolls of the General Nursing Council and the Central Midwives Board. The Board is responsible for postbasic training in England and Wales; as usual Scotland and Northern Ireland do things slightly differently-better or worse according to geographical viewpoint. The Board is 'Joint' in that it consists of both doctors and nurses covering a wide range of professional interests. Its first task was to review the needs of the trained nurse and to produce appropriate syllabuses of training in various fields. In this it has been impressively successful. The most recent syllabus, Course No. 989, is for a short course on the Principles of Community Psychiatric Nursing for Enrolled Nurses. Do not be misled by the high number; the system allows the interpolation of related courses in consecutive numbers. Nevertheless, there is still an impressive number of courses available. At the moment there are 64 courses.

The Board has a number of panels who recommend appropriate courses in their own field and if these are approved then plan the syllabus. Each syllabus outlines the aim of the course, gives general information about it and enumerates its objectives. It usually provides a reading list. Once a course has been agreed it is open to Schools of Nursing, Polytechnics and other organizations to apply for permission to establish it. On its staff the Board has a number of Clinical Nursing Studies Officers whose role is to assist organizations in setting up courses and to monitor progress.

Courses are of two main types. There are long ones of six to twelve months duration designed to introduce trained nurses to a new field of activity. The nurse may have had some superficial knowledge of the subject gained from earlier training or may be faced with the possibility of working in that field without adequate specialized information. These are designed to offer both theoretical and practical information of an intensive kind to enable the nurse to return to the work field as a knowledgeable member of the team, and often as a leader and specialist adviser. Examples are behaviour therapy and the developing field of community psychiatric nursing. Short courses of a few days to six weeks duration often on a day release basis are designed to bring an experienced nurse up to date with developments in a particular field, e.g. psychosexual counselling.

By their nature long courses tend to be few in number and inevitably may be remote from the place of work and residence of the majority of nurses. The nurse must be free to live away from home and needs the financial support provided by secondment by the Health Authority. It is thus expensive for an Authority to second the nurse and provide extra finance to offer replacement over a relatively long period. Short courses obviously are easier to cope with financially; where they are full-time the period is limited, but where a day release programme is used the courses need to be near to the place of work.

Most doctors are aware of the value of attending postgraduate meetings and hearing experts talk about recent advances in the field. It would be naive to pretend that many do not come away feeling that the speaker was teaching his grandmother to suck eggs; that in itself can be valuable, giving a feeling of selfsatisfaction that we are not so backward and out of date at St Somewhere or other. More important is the opportunity to discuss over coffee, or in the bar, points which have been raised or forgotten and to be able to say or to hear other people say that we do it differently in our part of the world.

The Joint Board courses are much more clearly defined and are organized with a well-defined educational aim and a series of objectives. Each nurse is assessed at the end of the long courses and given a certificate of proficiency if indeed proficiency has been attained. 
With the short courses a statement of attendance is offered. The Joint Board is therefore offering a mixture of postgraduate training leading to the equivalent of Diplomas and Membership of the various Colleges and the general practitioner requirement to attend a number of postgraduate meetings during the year. They do it differently-some would say that they do it better and that the doctors should emulate them. In the meantime it is important that doctors should be aware of the activities of the Joint Board, should encourage nurses to attend available courses and should be aware of courses in their own field which they should bring to the attention of suitable nurses. Furthermore, when the nurses return it is most important that they should be helped to use the knowledge which has been gained in a constructive and productive manner. There is a need for doctors to press the case for the financing of secondment to courses and also, where appropriate, for the setting up of courses in their own Area. Doctors expect postgraduate training for themselves and should support their nursing colleagues in their claims for similar post-basic professional education and training.*

* Copies of Notes on the Outline Curricula published by the Joint Board of Clinical Nursing Studies and current lists of centres approved to offer courses may be obtained free from the Joint Board at 1 78-202 Great Portland Street, London WIN 5TB. A stamped, self-addressed envelope accompanying your request would be appreciated.

\title{
MYTHS AND 'MIND'
}

\author{
By Norman E. CRumpton \\ Consultant Psychiatrist, Broadgate Hospital, Beverley
}

If the perpetuation of a myth leads to the saving of central Government funds, political parties and bureaucrats will eschew reality.

In such endeavours they will enlist to their aid any pressure group or society that can be easily deceived by fine phrases and ideals. One of the most consistent allies of the DHSS in this duplicity is the National Association of Mental Health.

In their publication 'MIND' October 1977, the position of the Community Mental Health provisions in Yorkshire, Humberside and the East Midlands is examined, the Government publication Better Services for the Mentally Ill forming the basis of their critique. There is a tenacity of purpose exhibited by 'MIND' directed towards pressurizing recalcitrant Local Authorities into wasting local finances in order to achieve what will be an inferior service for the mentally ill.

The first of the two myths which are perpetuated in this quest for more Local Authority Residential Care, Day Care and Social Clubs was created in 1961, postulating that mental hospitals would cease to have a raison d'etre within a decade.

The second pretension is that mental hospitals produce institutional neurosis where Local Authority Residences do not.
The first myth, continually refreshed and rehearsed by each new Ministry, enables the DHSS to neglect the only solid facility which is available in any quantity to the 'mentally and emotionally ill'-the psychiatric hospital.

The second proposition is equally fatuous, as it is systems and staff attitudes that cause institutionalization, not buildings.

How often does one go into the modern Local Authority Part III accommodation for the elderly and see the institutionalized 'wall-flowers' who have long disappeared from the psychiatric hospital ward? The Social Services have heard of institutionalization but fail to understand its nature and are insistent on repeating the same errors in patient care that psychiatric hospitals learnt to avoid before 1960 .

'MIND' states that patients who are well-cared for in hospital find on discharge that no one cares.

One asks, 'were such patients discharged simply to demonstrate to the DHSS that the hospital in question is progressive'? Too often patients are discharged who cannot achieve even primary survival standards in society. Such patients can live to their maximum capacity in one of the 'hostel' wards of a mental hospital, living satisfactory lives, virtually independent of nurses and doctors; moving freely into 